\title{
AN OVERVIEW OF INSTRUMENTATION FOR MEASURING ENVIRONMENTAL RADON AND RADON PROGENY
}

\author{
Andreas C. George
}

\begin{abstract}
Instruments for the measurement of radon and its progeny are based mostly on the detection of alpha particles and to some extent on the detection of beta and gamma emissions. The instruments and methods used depend on whether the technique measures radon or radon progeny, the type of radiation being detected and the duration of the measurement of which there are three types: grab or instantaneous, integrating and continuous. Other criteria used in the design of these instruments are field measurement applicability, portability, convenience, reliability and cost. With the recent increased demand for indoor radon and radon progeny measurements, instrument development has focused on the design of inexpensive mailable devices for short-term exposures used in screening studies, as well as on more complex and sophisticated instruments for both short-term and longterm measurements used in research programs.
\end{abstract}

\section{INTRODUCTION}

Radon and its progeny have come to be recognized as the largest single source of radiation dose received by the general public [1]. In recent years, elevated concentrations of radon and radon progeny were found in the northeastern United States and interest in measuring indoor radon levels escalated dramatically throughout the country. This renewed interest in measuring radon and radon progeny led to increased instrument research and development. As of this writing, more than 2 million indoor radon measurements have been made by commercial companies, federal, state and local government agencies in residential buildings, schools and the work place. The U.S. Environmental Protection Agency (EPA) has found that about $30 \%$ of the measured homes in several states had radon levels above the "action level guideline" of $148 \mathrm{~Bq} \mathrm{~m}^{-3}\left(4 \mathrm{pCi}^{-1}\right)$.

Although radon progeny are responsible for most of the radiation dose to target cells in the lungs, the parent radon supports and controls their concentration. Since radon measurements alone are generally adequate in providing information on the upper limit for the radiation exposure from radon progeny, they often become the measurement of choice. They are simpler, more convenient and less costly than radon progeny measurements.

\footnotetext{
The author is with the Environmental Measurements Laboratory, U.S. Department of Energy, 376 Hudson Street, NY, NY 100143621.
}

Because radon and radon progeny emit both alpha and beta particles, as well as gamma rays, various measurement techniques have been developed which utilize these types of radiation independently or in combination. The methods and techniques for the collection and measurement of radon and radon progeny in air can be divided into three categories: grab or instantaneous, integrating and continuous. The sampling devices can be further subdivided into active (requiring power to collect a sample) and passive (requiring no power). The choice of technique depends on the specific application, information needed, sampling time, instrument sensitivity and cost considerations. The selection of instruments included in this review is based on the experience of EPA gained during five rounds of proficiency testing [2] of radon and radon progeny measurements. Discussion of instruments and methods in this paper will be limited to the most used ones. Since the development of radon and radon progeny instruments is constantly expanding, some old and outdated monitoring devices have been omitted from this overview. Nor will large and complex instruments for outdoor measurements of radon and radon progeny be described here.

\section{PRINCIPLES OF DETECTION}

The measurement of ${ }^{222} \mathrm{Rn}$ is always based on the detection of either the alpha particles emitted by radon itself or the alpha, beta and gamma radiation of its decay products. These radiations can be measured using the following types of instruments and techniques.

1. Sealed ionization chambers, current and fast pulse types,

2. Scintillation detectors such as zinc-sulfide phosphor [ $\mathrm{ZnS}(\mathrm{Ag})]$,

3. Alpha particle spectrometers with silicon diodes, surface barrier or diffused junction detectors,

4. Gamma-ray spectrometers with $\mathrm{NaI}(\mathrm{Tl})$ scintillating crystals or germanium lithium (GeLi) semiconductors,

5. Registering of nuclear tracks in solid-state materials,

6. Interacting of radiation in thermoluminescent materials such as crystals or ceramics. 
The specific application of the above measurement techniques and instrumentation will be described in detail in the following sections.

\section{MEASUREMENT OF RADON AND RADON PROGENY BY GRAB SAMPLING}

In grab sampling methods, samples are collected over a short period of time, e.g., instantaneous for $10 \mathrm{~min}$, and analyzed shortly thereafter, usually within $4 \mathrm{~h}$. In some cases, analysis can be performed in the field. Grab sampling is very useful in locating sources of radon in a building as well as in guiding remedial action work, and in crosschecking and calibrating other methods and techniques. By making many measurements during different seasons of the year and times of the day, it is suitable for the rough assessment of the average indoor air concentration of radon and its progeny.

\section{A. Grab Sampling for Radon}

1) Ionization chambers: For highly accurate measurements of low concentrations of radon collected by grab sampling, ionization chambers are the instruments of choice [3]. However, both the current and fast pulse counting types are complex and costly instruments requiring highly trained operators. They are therefore mostly used as primary instruments and serve as standards for calibrating and evaluating the secondary instruments routinely used for measuring radon. They are often used to analyse grab samples of whole air collected outdoors and in special projects where radon levels are unusually low. Samples collected in the field in a variety of containers or trapped on activated carbon are subsequently transferred to the ionization chamber for analysis in the laboratory. Ionization chambers are constructed with electropolished stainless steel material to reduce the radiation background. Present day measurements are generally performed in sealed chambers usually after removal of water vapor and oxygen to facilitate the fast-pulse counting. The sample is transferred into the chamber with forming gas (85\% nitrogen and $15 \%$ hydrogen) through a platinum black catalyst. The water formed in the catalytic reaction is removed with Drierite. The lower limit of detection of a $2 \mathrm{~L}$ sealed ionization chamber for a $17 \mathrm{~h}$ count is $0.7 \mathrm{mBq}$ of radon.

2) Scintillation cell: The scintillation cell method is one of the oldest and most widely used grab sampling tools both in the laboratory and in the field [4], [5]. Scintillation cells range in size from 0.09 to $3.0 \mathrm{~L}$ and they are made by using metal, glass or plastic containers coated internally with silver activated $\mathrm{ZnS}(\mathrm{Ag})$ powder. The bottom of the container is usually transparent to allow light photons produced in the scintillator to be detected. If the internal coating is very thin, the bottom of the container can also be coated without significant loss of light photons [5]. For counting the light photons, the scintillation cell is coupled to a photomultiplier tube assembly system. The principle of detection is the counting of light photons resulting from the interaction of alpha particles from radon and radon progeny decaying in the cell with the $\mathrm{ZnS}(\mathrm{Ag})$ phosphor. $\mathrm{ZnS}(\mathrm{Ag})$ emits light in the range of $450 \mathrm{~nm}$ so photomultiplier tubes with a peak response near this wavelength are generally used. Scintillation cells can be filled by exposing evacuated cells (instantaneous), or by flowing air through at ambient conditions for 1-5 min. The advantage of using a scintillation cell is that it eliminates the need for sample transfer before counting. However, samples from larger containers or from systems that concentrate environmental levels of radon by cryogenic processes can be transferred into them for counting if desired. Scintillation cells are ideal for diagnostic and remediation work because multiple samples can be collected simultaneously in different locations to determine indoor radon sources and to study the effects of mitigation techniques on radon level reduction. The scintillation cell can be termed the workhorse of the radon measuring instruments.

Measurement errors using scintillation cells can result from improper calibration, leaking cells and malfunctioning or an improperly calibrated photomultiplier tube system. Calibrations with a particular scintillation cell-photomultiplier tube system should not be used for another calibration unless both systems are cross-calibrated. The sensitivities of scintillation cells range from 0.8 to $16 \mathrm{cph}$ per $\mathrm{Bq} \mathrm{m}{ }^{-3}$ for sizes ranging from $0.1 \mathrm{~L}$ to $3.0 \mathrm{~L}$, respectively. Commercial plastic scintillation cells cost from $\$ 50$ to $\$ 100$ each and glass and metal cells from $\$ 200$ to $\$ 400$ each. The counting system costs between $\$ 1500-\$ 2000$. When properly maintained, scintillation cells can be reused for years. Fig. 1 shows several types of scintillation cells along with other grab sampling containers from which a sample can be transferred into a scintillation cell for alpha counting.

\section{B. Grab Sampling for Radon Progeny}

Although the collection and analysis of radon progeny is more difficult and costly than that of radon, it is very important in the precise assessment of the radiation exposure to the respiratory system and in the study of the physical properties and behavior of the individual radon progeny in indoor or underground environments. All methods for the determination of airborne radon progeny are based on collection of radon progeny atoms or atoms associated with atmospheric particulates on high efficiency filter media by drawing a known volume of air in a known time, usually 2$10 \mathrm{~min}$, followed by alpha counting the collected radioactivity during or after sampling for specified time intervals. Fig. 2 shows a recommended sampling arrangement for the collection of a sample on a filter.

The most popular radon progeny analysis technique is based on gross alpha counting, in which the alpha particles from ${ }^{218} \mathrm{Po}$ and ${ }^{214} \mathrm{Po}$ are counted without discrimination for the two different energies. The counting system consists of a photomultiplier tube and $\mathrm{ZnS}(\mathrm{Ag})$ scintillator usually in contact or in very close proximity to the filter with the 


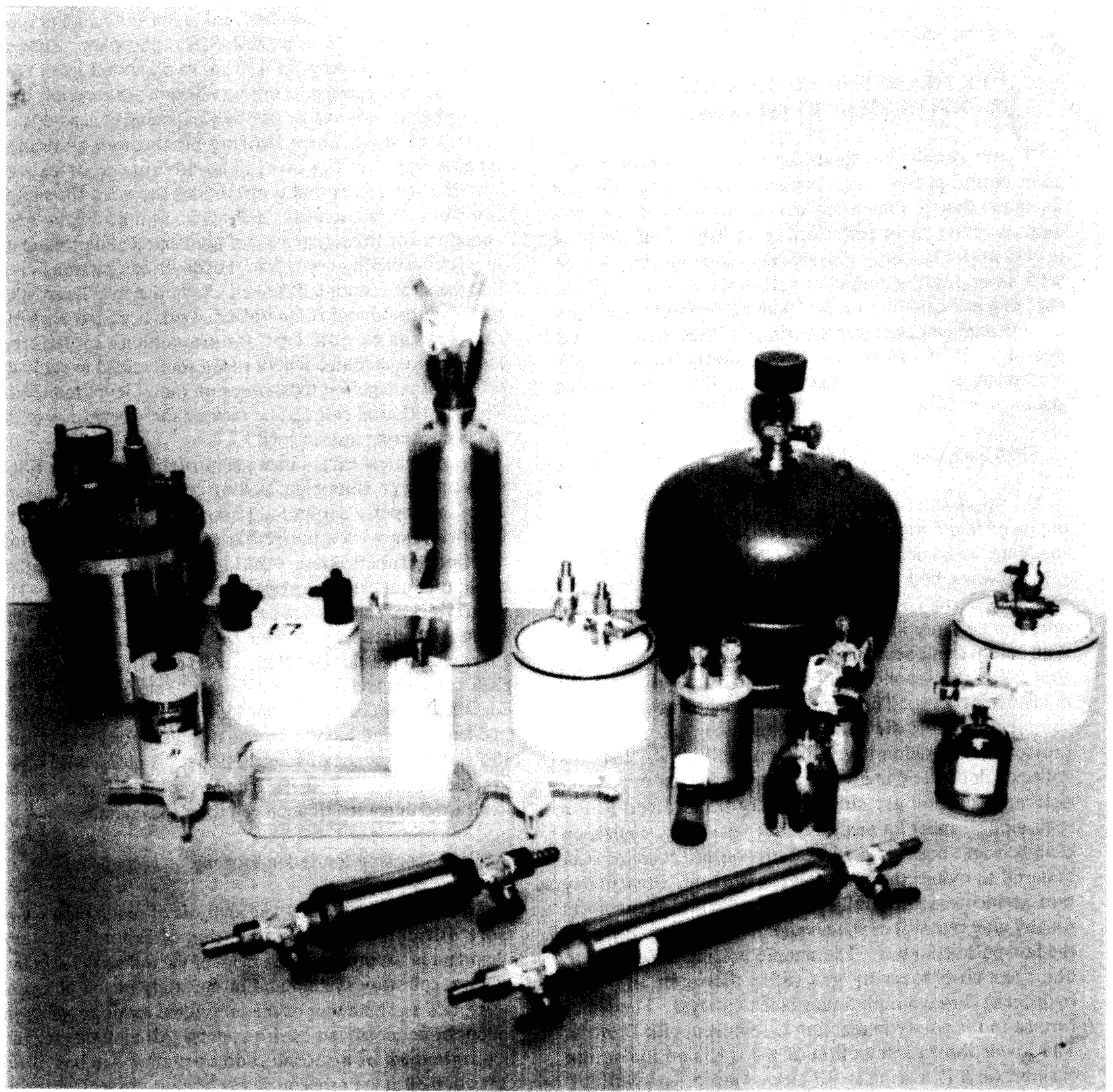

Fig. 1 Scintillation cells and radon sample containers.

collected radioactivity. A number of different counting regimes can be used [6] [7] to determine the individual activity concentrations of ${ }^{218} \mathrm{Po},{ }^{214} \mathrm{~Pb}$ and ${ }^{214} \mathrm{Bi}$ and their contribution to the total potential alpha energy concentration (PAEC). A measurement is usually completed in 30 to $40 \mathrm{~min}$ including the sampling time. The PAEC in air is represented by a special unit, the working level (WL): $1 \mathrm{WL}$ is defined as any combination of the radon progeny in $1 \mathrm{~L}$ of air such that the total alpha energy released is $1.3 \times 10^{5}$ MeVor $2.08 \times 10^{-8} \mathrm{~J}$. Since there are three radon progeny of interest, their concentrations represent three independent variables and this requires three measurement periods resulting in three independent simultaneous equations to determine their individual concentrations in air [6]. For the 


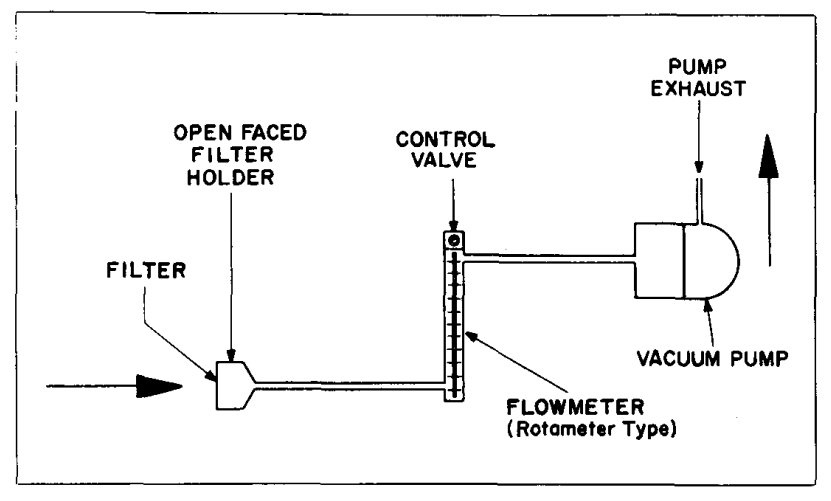

Fig. 2 Radon progeny sampling arrangement.

determination of environmental levels of radon progeny, gross alpha counting is preferred because it is easier and it can be used with higher air flow rates that yield higher measurement sensitivity than one can obtain with alpha spectrometry. The lower limit of detection for $218 \mathrm{Po}$, ${ }^{214} \mathrm{~Pb},{ }^{214} \mathrm{Bi}$ and the PAEC for a $5 \mathrm{~min}$ sample at a flow rate of $10 \mathrm{~L} \mathrm{~min}^{-1}$ is $25 \mathrm{~Bq} \mathrm{~m}^{-3}, 7 \mathrm{~Bq} \mathrm{~m}^{-3}, 22 \mathrm{~Bq} \mathrm{~m}^{-3}$ and $50 \mathrm{~nJ} \mathrm{~m}^{-3}$, respectively. The detection limit improves with higher flow rates, longer sampling and by counting during sampling. A very popular alternative method for determining occupational exposures consists of a single gross alpha counting interval between $40-90 \mathrm{~min}$ after the end of lampling at the field site and yields results in PAEC only [8].

A more sophisticated and costly analysis method is alpha spectrometry. It is used extensively in the laboratory and occasionally in special field research situations where more precise measurements of individual radon progeny are desired. Surface barrier or diffused junction detectors are generally used with multichannel analysis [9], [10]. The detectors provide high resolution spectra of the alpha particles from ${ }^{218} \mathrm{Po}(6.0 \mathrm{MeV})$ and ${ }^{214} \mathrm{Po}(7.7 \mathrm{MeV})$ or any other alpha emitters collected on the filter. For situations where there are other significant concentrations of interfering alpha emitters such as ${ }^{220} \mathrm{Rn}$ or ${ }^{219} \mathrm{Rn}$, alpha spectrometry is the best method since gross alpha counting will not differentiate between them. Alpha spectrometry can provide measurements of radon progeny concentrations of $<20 \mathrm{~Bq}$ $\mathrm{m}^{-3}$ with a precision of better than $20 \%$ at a flow rate of $10 \mathrm{~L}$ $\min ^{-1}[10]$. The contribution of thoron progeny in grab sampling for radon progeny in typical indoor environments is insignificant for the short duration samples.

With the recent advances in instrumentation and computer technology, grab sampling for radon progeny using either method for counting is becoming more automated, allowing unattended operation during sampling and analysis. This recent feature eliminates opcrator errors which are often encountered in manual procedures.
Errors in measuring individual radon progeny and PAEC with either gross alpha counting or alpha spectrometry generally result from (1) inaccurate air sample volume measurements, (2) poor filter media, or (3) poor counting geometry and counting efficiency. Inaccuracy in flow rate measurement can result from improper calibration of the air metering device, an unstable air pump, faulty filter holder or incorrect timing. Filter media should be thin, of small pore size, of low flow resistance and have good surface deposition characteristics and high collection efficiency. Since the counting efficiency of the detector is a function of energy, it should be determined with an alpha standard source having nearly the same energies as those possessed by radon progeny. The counting efficiency also depends on the distance of the detector from the filter sample and on its relative size and shape. Counting geometries that are highly energy dependent should be avoided. Counting errors will also occur because of the random nature of radioactive decay. To improve counting statistics, large volumes of air should be sampled, the detector-sample assembly should be designed to maximize counting efficiency and counting should be carried out during as well as after sampling.

\section{INTEGRATING MEASUREMENT METHODS FOR RADON AND RADON PROGENY}

The most popular methods for monitoring radon and radon progeny are based on integrating sampling techniques where the measurement is carried out over a period of days, weeks, months, or up to a year. It yields a single value representing the average concentration over the measurement period in question. The early development of integrating instruments was exclusively carried out by the Environmental Measurements Laboratory (EML) and the Office of Radiation Programs, EPA using in-house developed instruments to monitor for radon and radon progeny in background locations and at sites contaminated with uranium and radium tailings. These instruments consisted of passive environmental monitors (PERM) and radon progeny integrated sampling units (RPISU) [11], [12]. Recent commercial development has focused on simpler, portable and in many cases mailable devices that can be deployed inside buildings by home owners. Indoor measurements made with these newer integrating devices are sufficiently sensitive to measure typical radon levels and they avcrage out the short-term fluctuations that normally make a grab sample measurement difficult to interpret. In most situations, analysis of the integrated sample is performed in a laboratory setting. At present, there are commercial active and passsive integrating instruments for radon, but only active devices for radon progeny.

\section{A. Passive Integrating Methods for Radon}

1) Solid-state nuclear track detectors: The principle of detection of nuclear track detectors is based on the production of alpha particle tracks in solid-state materials, 
such as cellulose nitrate (LR-115 Kodak-Pathe) and allyl diglycol carbonate (CR-39) plastic films [13]. The plastic detector is usually placed inside a small container into which only radon diffuses through a filter that excludes radon progeny. Alpha particles from radon and from radon progeny produced inside the container irradiate the plastic detector and produce damage tracks. After exposure, the tracks are made visible by chemical or electrochemical etching, usually in a $\mathrm{NaOH}$ solution. Electrochemical etching is preferable because it produces large-diameter tracks and simplifies track counting. The track density is determined by manual scanning and counting or by an automated optical scanning system. In this method the detector is not sensitive to beta and gamma radiation and correction for ambient background is not necessary.

The alpha track method is relatively insensitive. Therefore, under normal environmental conditions, exposure periods ranging from three months to a year are typically used. For this reason, alpha track detectors are preferred in situations where confirmation of measurements made with short-term integrating devices is needed or for determining the average annual exposure. The analysis is labor intensive and is usually performed by very large laboratories. The lower limit of detection for a 3-month exposure is 2-8 $\mathrm{Bq} \mathrm{m}^{-3}$ depending on the size of the scanned area of the detector. The cost per single exposure is about $\$ 25$. Some factors that may affect the performance of these detectors are variability in response of detectors from different production batches and from nonuniform plateout of the radon progeny inside the container. Because of the variability of solid-state nuclear track plastics (thickness, acquired background and temperature during preparation), exceptional product quality control is required. Also, a quality assurance measurements program must be in place, involving frequent calibrations for accuracy and duplicate exposures for precision estimates.

2) Activated carbon method: For integrating periods of up to 7 days, the activated carbon collector has become the most popular monitoring device in use today for indoor radon level assessment [14]. Collectors come in different sizes and configurations. This technique utilizes passive diffusion to collect radon from ambient air by adsorption onto activated carbon and simple detection techniques to detect the alpha, beta and gamma rays emitted by the radon progeny. The collector with the adsorbed radon on the carbon is sealed after exposure and returned for analysis to a central laboratory. Counting is usually performed after a minimum of $3 \mathrm{~h}$ have elapsed from the end of exposure to allow equilibration between radon and its progeny. The analysis is straightforward and utilizes equipment that is very common to most radiological laboratories. There are two different detection methods used: (1) gamma counting which is usually done on a $\mathrm{NaI}(\mathrm{Tl})$ system with a multichannel pulse height analyzer [14], [15]; or (2) alpha and beta counting in a liquid scintillation system [16].

The collectors used with gamma counting contain from $25 \mathrm{~g}$ to $200 \mathrm{~g}$ of carbon and can be open faced, with limited open area, or have a diffusion barricr to lessen the effects of interfering water vapor. Open-faced collectors are affected more by water vapor and by widely varying radon concentrations than collectors with limited open areas or with diffusion barriers. Because water vapor can affect all types of activated carbon collectors, their performance must be evaluated by calibration under different environmental conditions. The integration period of a collector can be increased to more than a week if steps are taken to reduce adsorption of water vapor which competes with radon for the active sites of the carbon bed.

In gamma counting, the net areas under the peaks from $214 \mathrm{~Pb}(0.242 \mathrm{MeV}, 0.295 \mathrm{MeV}$ and $0.352 \mathrm{MeV})$ and ${ }^{214} \mathrm{Bi}$ $(0.609 \mathrm{MeV})$ are used to determine the average concentration of radon during the sampling period. The counting efficiency with a $\mathrm{NaI}(\mathrm{Tl})$ system is about $10 \%$ and the sensitivity becomes higher with collectors that contain more carbon. Typical carbon collectors used with gamma counting can be fabricated at a cost of $\$ 2$ to $\$ 4$ each and can be recycled many times after simple regeneration by heat. The lower limit of detection depending on collector size ranges from 3.7 to $7.5 \mathrm{~Bq} \mathrm{~m}^{-3}$ of radon for an exposure period of 4 days. The counting system's cost runs from $\$ 6 \mathrm{~K}$ $\$ 15 \mathrm{~K}$.

Collectors used with the liquid scintillation method are usually much smaller, containing only 1-2 $\mathrm{g}$ of activated carbon, but the analytical steps are more time consuming than the simple procedure used in the gamma analysis. After exposure, the radon adsorbed on the carbon is eluted into a scintillant cocktail, a step that may require up to several hours for the complete transfer of radon from the carbon into the cocktail mixture.

The requirement of radon elution in the liquid scintillation method is somewhat offset by the ease of detecting the three alpha and the two beta particles emitted by radon progeny, resulting in a gain of 2.5 in sensitivity over gamma-ray detection. The counting efficiency of the liquid scintillation method is essentially $100 \%$ and the signal-to-noise ratio with alpha and beta counting is higher than that obtained with conventional gamma-ray counting systems. This helps to overcome the lower sensitivity of collectors with very small amounts of carbon. The lower limit of detection is about 3.7 $\mathrm{Bq} \mathrm{m}{ }^{-3}$ with a 2-day exposure time. Because of the small size of the collector, the integration period is limited to $<3$ days, especially in very humid environments where water vapor uptake competes with radon adsorption. The collector cannot be reused, but it costs only about $\$ 1$ to replace. The counting system usually costs from $\$ 15 \mathrm{~K}-\$ 30 \mathrm{~K}$.

As an integrating collector, the passive activated carbon devices offer advantages such as simplicity, up to 7 days of integrated exposure, and cost effectiveness. Because the halflife of ${ }^{222} \mathrm{Rn}$ is 3.82 days, the exposure period cannot be longer than about 7 days. With a proper quality assurance program, the activated carbon technique represents the most practical method for reasonably accurate and precise measurements of the average indoor radon concentrations. According to a press release by EPA's Office of Radiation Programs, roughly 2 million of the 80 million single family 
homes in the United States have been screened for radon through both private and governmentally-sponsored activities. Approximately $75 \%$ of the measurements were made with activated carbon devices.

3) Electret-ionization chamber method: This recently developed passive monitoring device consists of a conducting plastic chamber with an electret at the bottom and a filtered inlet on the top [17]. It is small in size with a sensitive volume of $0.21 \mathrm{~L}$. The radiations associated with the radon entering through the filtered inlet and the progeny formed inside the chamber generate ions which are collected by the electret. The electret serves a dual purpose, as a source of an electric field and as a quantitative sensor. The ions formed inside the chamber during the exposure cause the surface voltage of the electret to drop in proportion to the integrated radon concentration. The voltage drop is determined from measurements before and after exposure. The voltage reader is a sensitive portable electrometer assembly that can measure the electret surface voltage directly in volts by a noncontact method.

The main advantage of the electret-ionization chamber is that the results can be obtained in the field immediately after exposure and the monitor can be used at other sites as long as there is sufficient charge on the electret. There are two types of electrets, thin and thick, and they determine the sensitivity of the method. The more sensitive electrets are thick and are used for short-term radon measurements (up to 7 days), yielding a voltage drop of about $0.054 \mathrm{~V}$ per Bq m$~_{-3}$ in 1 day $\left(2 \mathrm{~V} / \mathrm{pCi} \mathrm{L}{ }^{-1}\right.$ day). The long-term electret is about 12 times less sensitive than the standard short-term electret and can be used for integrating periods of 1-12 months. Electret ion chambers are true integrators of varying concentrations of indoor radon. These devices are not affected significantly by the variations in humidity and temperature during exposure. The disadvantage of the device is that it responds to natural gamma radiation, which can be variable from site to site, and the possibility of discharging the electret after being accidentally touched exists. The lower limit of detection for the short-term electret-ionization chamber is $7 \mathrm{~Bq} \mathrm{~m}^{-3}$ of radon for a 3 day exposure. The device can be mailed for testing and returned for analysis in a central laboratory at a cost of about $\$ 25$. The voltmeter costs about $\$ 1000$.

4) Solid-state detection monitors: These devices are sophisticated radon detection systems which utilize microcomputer technology to store and analyse the data. Radon diffuses into the device through a filter and the alphas from radon progeny that are produced inside its sensitive volume are detected by a solid-state silicon detector. A commercial version of this instrument is available, but is rather expensive for screening purposes. It can be very useful in premitigation and postmitigation diagnostic data collection. The lower limit of detection is $4 \mathrm{~Bq} \mathrm{~m}^{-3}$ in a 2 day exposure. Fig. 3 shows several types of passive integrating radon monitoring devices.

\section{INTEGRATING RADON PROGENY MONITORS}

Several variations of radon progeny monitors have been developed to integrate the radioactivity collected on a filter over a period of several days. All of these monitors work on the same principle. Air is pumped at a constant flow rate through a sampling head consisting of a filter-detector assembly. The sensing device can be thermoluminescent dosimeter (TLD) chips, solid-state nuclear track detectors (track etch), alpha scintillation phosphors, surface barrier or diffused-junction detectors and electret ion chamber detectors. In all cases, the detector is positioned in close proximity to the filter, so that alpha particles emitted by the radon progeny collected on the filter irradiate the detector.

1) TLD system: The TLD chips used are generally either calcium fluoride dysprosium $\left(\mathrm{CaF}_{2}: \mathrm{Dy}\right)$ or lithium fluoride (LiF) [11], [18]. For indoor use the air flow is provided by an acoustically-shielded pump at flow rates ranging from 0.1 to $4 \mathrm{~L} \mathrm{~min}^{-1}$. The measurement is usually made over a period of several days. Upon completing the exposure, the filter-head assembly is returned to a central laboratory where the chips are analyzed in a TLD reader. During exposure, the alpha particles from radon progeny strike the TLD chip in the filter head, creating electron hole pairs which may enter a metastable state above the ground state. The TLDs are heated at a uniform rate in a commercial reader under strictly controlled environmental conditions. The amount of light emitted by the TLDs as the electrons and holes recombine is detected by a photomultiplier tube and is proportional to the integrated radioactivity collected on the filter paper during sampling. The contribution of the gamma background radiation during the exposure is measured with a second TLD chip which is housed in the filter-detector assembly, but is shielded from the alpha radioactivity emitted by the filter.

The preparation and handling of the TLD chips before and during analysis must follow exact and established procedures for any deviation from them will result in questionable measurement results. The PAEC lower limit of detection of integrating TLD instruments depends on the pumping flow rate, filter-detector geometry, and the TLD material, and ranges from $2.1 \mathrm{~nJ} \mathrm{~m}^{-3}$ to $10.4 \mathrm{~nJ} \mathrm{~m}^{-3}$ (0.0001 to 0.0005 WL) for a week-long exposure. TLD readers cost between $\$ 6 \mathrm{k}$ to $10 \mathrm{~K}$, and the integrating instruments from $\$ 1 \mathrm{~K}$ to $1.5 \mathrm{~K}$. The method is labor intensive and requires highly trained personnel and exceptional measurement quality control. In highly dusty environments, the filter may clog up, especially if the monitor uses a high flow rate. Despite these disadvantages, these types of instruments have been used extensively in the past in EPA and DOE radon research projects with success.

2) Solid-state nuclear track detector systems: A similar filter-head assembly that is used with the TLD instrument can be used with other detector materials, one of 


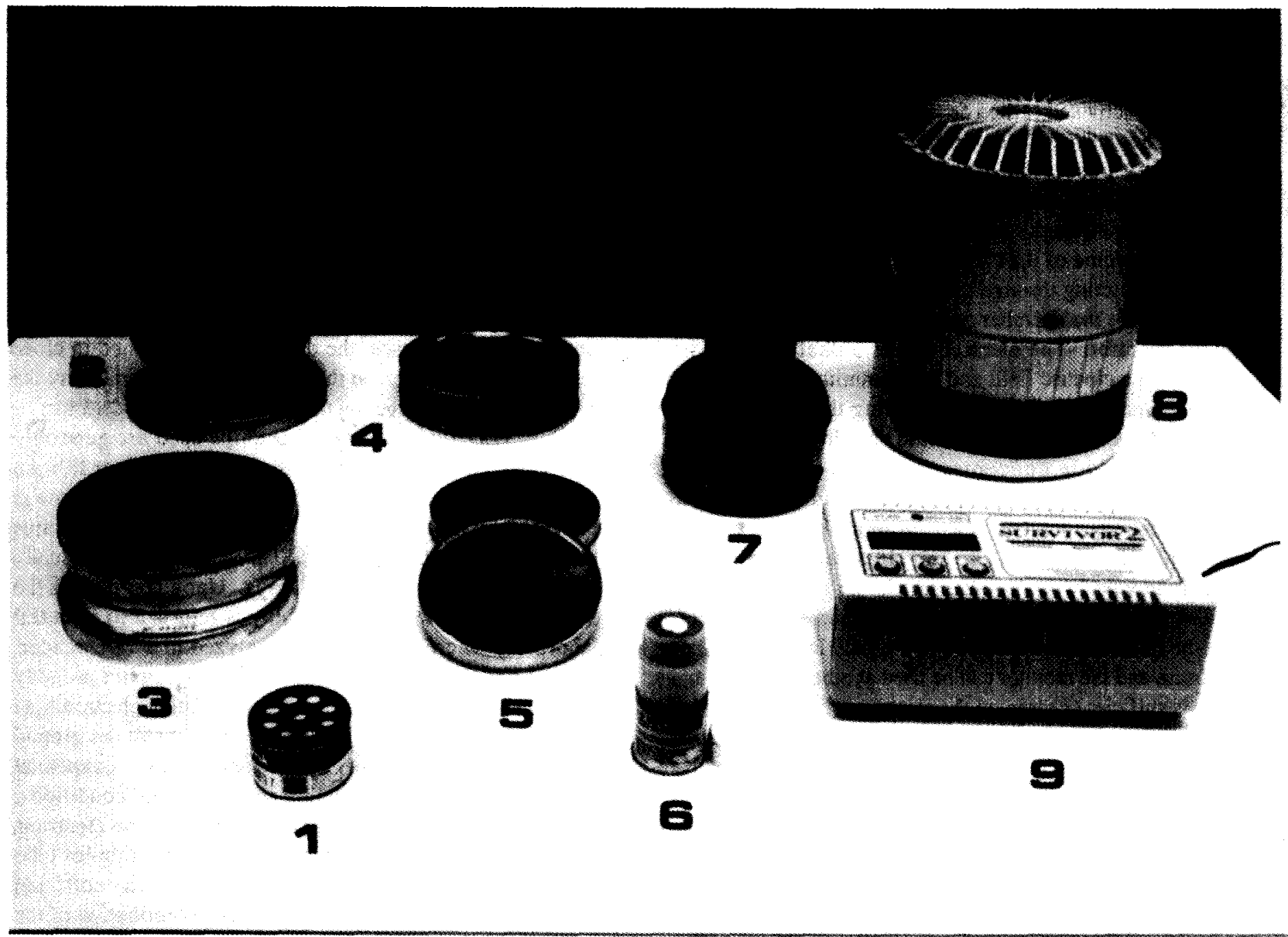

Fig. 3 Passive integrating radon monitoring devices:

1. Solid-state track etch detector,

2. Original EML open-faced activated carbon collectorgamma counting,

3. Open-faced EML activated carbon collector-gamma counting,

4. Diffusion barrier activated carbon collector-gamma counting,

which is the nuclear track detector. One commercially available device using track-etch technology uses a detector of high quality solid-state carbonate base CR-39 plastic film [12]. The detector assembly is constructed in such a way so as to differentiate between radon and thoron progeny by means of their alpha energy differences. This is accomplished by using different collimators and absorbers in a fixed exposure geometry between the filter and the plastic detector. The tracks formed in the plastic detector are read using image analysis. The pump, drawing air at $1 \mathrm{~L} \mathrm{~min}^{-1}$ through the filter-detector head, is an inexpensive modified
5. EML diffusion barrier activated carbon collector-gamma counting

6. Diffusion barrier activated carbon collector-liquid scintillation, alpha beta counting,

7. Electret ionization chamber monitor,

8. Solid-state radon detector,

9. Pulse ionization chamber monitor.

aquarium pump. The filter-detector head can be fabricated using injection moulding techniques and can be massproduced at reasonable cost. The lower limit of detection with this method is $4.2 \mathrm{~nJ} \mathrm{~m}^{-3}(0.0002 \mathrm{WL})$, for a week-long integrated exposure. A clear advantage of this device over the TLD method is that the entire monitoring device is small enough to be sent for exposure and returned by mail to a central laboratory for analysis. The main disadvantage of the method is the exceptional quality control that must be exercised when using solid-state nuclear track detectors.

3) Total gross alpha detector systems: The integrated 
measurement of radon progeny collected on a filter can also be performed by gross alpha counting using: scintillation, surface barrier or diffused junction detectors in the same way as performed for radon progeny grab sampling. One such commercial instrument is a small hand-held monitor with an enclosed pump that draws air at a rate of $1 \mathrm{~L} \mathrm{~min}-1$. The alpha particles from radon progeny collected on the filter are counted with a semiconductor detection system, and the counts are displayed on a digital readout which can be converted to PAEC on-site. The lower limit of detection is about $20 \mathrm{~nJ} \mathrm{~m}^{-3}$ for $(0.0009 \mathrm{WL})$ for 1 day integrated exposure. The instrument is easy to use for screening or for long-term averaging of radon progeny inside buildings. The disadvantage is the relatively high cost for a single measurement since a trained operator must install the device on site with a cost of up to $\$ 100$. The monitoring device costs about $\$ 2 \mathrm{~K}$.

\section{CONTINUOUS RADON AND RADON PROGENY MONITORS}

A continuous method for measuring radon or radon progeny is one where sampling and analysis occur simultaneously providing real-time measurement results. This is very useful and desirable in situations where radon concentrations may change significantly and rapidly. It is also a very informative method for studying the effects of ventilation on indoor radon levels, as well as for the determination of the average radon or radon progeny concentration. These devices are also used to monitor radon and radon progeny exposure chambers used in research and for other instrument calibration and standardization. Radon measurements made with continuous monitors are easier to make than are radon progeny measurements because problems associated with particulate sampling are eliminated and high flow rates are not required. Measurement intervals generally range from a minimum of $15 \mathrm{~min}$ to $60 \mathrm{~min}$ with useful results obtainable in 2 to $3 \mathrm{~h}$ of continuous sampling and counting. The primary advantage of continuous radon and radon progeny monitors is that they provide real-time radon concentration data on a frequent basis. The disadvantages are that they are very expensive and complex instruments requiring trained personnel to operate them.

\section{A. Continuous Radon Monitors}

1) Continuous scintillation cell monitor: This collection and detection device consists of a two port scintillation cell coated internally with $\mathrm{ZnS}(\mathrm{Ag})$ phosphor. It is an identical system to that used for grab sampling except air containing radon only is drawn through it continuously. Scintillation cell size is dictated by the size of the photomultiplier tube and housing. The principle of detection is the same as that used in grab sampling except here the air drawn through the cell is continuously filtered to remove the airborne radon progeny and any other particulates. The light pulses produced on a continuous basis from the alphas from radon and from radon progeny deposited on the internal surfaces of the scintillation cell are detected by the photomultiplier tube.

Since the effective half-life of radon progeny is about 31 $m$ in, there is a time-resolution limitation, and the measurement interval is limited to $2-3 \mathrm{~h}$ for accurate measurement results. The count rate does not change quickly with sudden fluctuations in radon concentration, and to overcome this weak point, the calibration of the device often incorporates a look-back calculation of five $30 \mathrm{~min}$ intervals to improve its temporal response [19], [20]. In practice, to measure varying radon concentrations accurately, corrections for the contribution of radon progeny from the prior 2 to 3 counting intervals should be taken into consideration in the calibration of the flow-through scintillation cell. Most commercial monitors do not take this look-back correction into consideration. Commercial continuous scintillation cell monitors generally cost from $\$ 2 \mathrm{~K}$ to $\$ 4 \mathrm{~K}$ depending on the amount of computer software. The lower limit of detection depends on the size of the scintillation cell and ranges from 1 to $37 \mathrm{~Bq} \mathrm{~m}^{-3}$ for a 30 min counting interval. A number of continuous scintillation cell monitors are commercially available.

2) Passive diffusion continuous radon monitor: This device is essentially the same as the scintillation cell monitoring instrument minus the air pump. Air enters the sensitive volume of the modified scintillation cell by diffusion through $1 \mathrm{~cm}$ thick foam material that removes radon progeny and other airborne particulates. The principle of detection is the same as that for grab and continuous scintillation cell monitors. Counting is usually done on an hourly basis. The lower limit of detection for a $1 \mathrm{~h}$ counting interval is about $37 \mathrm{~Bq} \mathrm{~m}^{-3}$. A commercial version of this monitoring device is available.

A second type of passive device for continuous measurement of radon is a portable pulse ion chamber. Air enters the ionization chamber (effective volume of $0.18 \mathrm{~L}$ ) by diffusion. The radon progeny are removed electrostatically and pulses only from the radon decay are detected by a unique electrometer. The half-time response of the device is about $40 \mathrm{~min}$, with a lower limit of detection of $18 \mathrm{~Bq} \mathrm{~m}^{-3}$ for an hourly exposure. The instrument, with its portable microprocessor-based data acquisition system, can be very useful for both screening and follow-up radon measurements. It provides real-time tracking of varying radon concentrations, along with hourly and on-command printouts. The commercial device is running about $\$ 3 k$; complete with the data acquisition system.

A third passive device is the diffusion radon only-monitor which, as the name implies, detects radon only [21]. The collection and sensing device is a modified scintillation cell with a charged electret that removes the radon progeny produced inside the cell before they are deposited on the $\mathrm{ZnS}(\mathrm{Ag})$ detecting phosphor, so that only the alpha pulses from radon are detected and counted. The proper spacing of the electret from the photomultiplier tube and the size of the sensitive volume determine the sensitivity of the device. The 
time response for this device is $<15 \mathrm{~min}$ with a lower limit of detection of about $10 \mathrm{~Bq} \mathrm{~m}^{-3}$ over a 15 min counting interval. The instrument is very useful for research purposes, for monitoring radon calibration facilities and for mitigation work. The high cost of this device ( $\$ 3 \mathrm{~K}$ to $\$ 4 \mathrm{~K}$ ) renders its use for screening purposes somewhat impractical.

\section{B. Continuous Radon Progeny Monitors}

Several commercial developers of radon progeny integrating instruments followed the lead of the EML [22], and began to automate these instruments for operation on a continuous basis. In these newly-developed instruments, air is sampled continuously through a filter-detector assembly using an air pump. The alpha radioactivity on the filter is integrated over short-time intervals. They are not truly continuous, but rather collect and analyze samples at intervals from several minutes to an hour. The difference between this method and the integrating method for measuring radon progeny is the introduction of automation to facilitate more frequent sampling and counting. The monitoring device typically contains a microprocessor that stores the number of counts and elapsed time. It can be programmed to run continuously, record data or if desired provide the total integrated PAEC. The detectors used are usually solid-state or diffused-junction types, which detect alpha particles from 2 to $8 \mathrm{MeV}$ emitted by 218 Po and ${ }^{214} \mathrm{Po}$. The counting rate is directly proportional to the number of alpha particles emitted by the radon progeny on the filter and the efficiency is around $20 \%$. A calibration factor is applied to the count rate to calculate the radon progeny concentration after exposure of the monitoring device to known concentrations of radon progeny. The instrument response is in cps per $\mathrm{J} \mathrm{m}^{-3}$.

The need for more frequent measurements and low flow rates associated with compact instruments must be balanced against poorer counting statistics. To overcome this problem, the instrument must usually be set to integrate the counts for 30-60 min. By adapting a recorder or any other electronic device that acquires data on a frequent basis, radon progeny fluctuations can be observed on-site. An added feature of the continuous radon progeny monitors is computer interphase capability allowing customized programming to meet different sampling protocols. The higher sensitivity, reduction in labor and ease with which these devices work have led to their replacing TLD integrating monitors. However, the disadvantages of these instruments include their relatively high cost and the need for a trained operator. The cost for a single measurement over several hours runs between $\$ 100-\$ 200$. For these reasons, they will remain in the hands of radon measurement companies and mitigators, in research laboratories and in radon progeny calibration facilities. Several versions of continuous radon progeny monitors are commercially available.

\section{DISCUSSION AND SUMMARY}

The major methods and techniques for measuring radon and radon progeny in indoor environments have been reviewed with regard to the measurement principle, field applicability, degree of convenience, cost effectiveness, sensitivity and accuracy. The three main categories of sampling and measurement, grab or instantaneous, integrating and continuous have been described. The information provided should help in the selection of an instrument that closely serves user needs and should provide instrument developers with sufficient background knowledge to undertake the research necessary to improve them. The present state of the art in the measurement of radon and radon progeny has been developed to the point where there are candidate instruments for almost every conceivable field application. At present, there is a strong need for rapid screening of indoor environments for possible high concentrations of radon and radon progeny. To fill this need, instruments that integrate for a few days are adequate. Activated carbon and electret ion chambers are increasingly being used by many radon measuring companies. They are reliable, inexpensive and provide results usually within 1-2 weeks. Instruments that use grab sampling methods can be very useful in diagnostic situations and where immediate results are required. For research purposes on radon and radon progeny transport, behavior, diagnostics and mitigation, more sophisticated continuous monitors are preferred.

The ability to obtain accurate measurements at low concentrations depends on the qualifications of the operator who uses properly calibrated instruments for a specific application. Some commercial instruments are calibrated based on theoretical grounds only, which is hardly adequate. The instruments are usually made of individual component parts performing different functions in a whole system and the entire system must be calibrated under conditions that approximate those in actual field situations. Filters, filter holders, pumps, flowmeters, alpha and gamma standard sources should be incorporated in the overall calibration and evaluation procedures since any deficiency in any part of the system can lead to inaccurate measurement results and to potentially erroneous estimation of the human exposure to radon and radon progeny.

\section{REFERENCES}

[1] National Council on Radiation Protection and Measurements, "Ionizing radiation exposure of population of the United States," NCRP Report N 93, Sept. 1987.

[2] U.S. Environmental Protection Agency, "Indoor radon and radon decay product measurement protocols," Report No. EPA 520-1/89-009, March 1989. 
[3] I. M. Fisenne and H. W. Keller, "The EML pulse ionization chamber systems for $222 \mathrm{Rn}$ measurements," USDOE Report EML-437, New York, NY, March 1985.

[4] H. F. Lucas, "Improved low-level alpha-scintillation counter for radon," Rev. Sci. Instrum., vol. 28, pp. 680-683, Sept. 1957.

[5] A. C. George, "Scintillation flasks for the determination of low level concentrations of radon," Proceedings of the Ninth Mid-Year Topical Symposium of the Health Physics Society, pp. 112115, Feb. 1976.

[6] J. W. Thomas, "Measurements of radon daughters in air" Health Phys., vol. 23, pp. 783-789, Dec. 1972.

[7] O. G. Raabe and M. E. Wrenn, "Analysis of the activity of radon daughter samples by weighted least squares," Health Phys., vol. 17, pp. 593-605, Oct. 1969.

[8] H. L. Kusnetz, "Radon daughters in mine atmospheres," A field method for determining concentrations," Am. Ind. Hyg. Assoc. J., vol. 17, pp. 85-88, March 1956.

[9] D. E. Martz, D. F. Holleman, D. E. McCurdy and, K. J. Schiager, "Analysis of atmospheric concentrations of $\mathrm{RaA}, \mathrm{RaB}$ and $\mathrm{RaC}$ by alpha spectroscopy," Health Phys., vol. 17, pp. 131-138, July 1969.

[10] W. W. Nazaroff, "Optimizing the total alpha threecount technique for measuring concentrations of radon progeny in residences," Health Phys., vol. 46, pp. 395-405, Feb. 1984.

[11] A. C. George, "A passive environmental radon monitor," in Radon Workshop, USDOE HASL-325, pp. 25-30, New York, NY, July 1977.

[12] K. Schiager, "Integrating radon progeny air sampler," Am. Ind. Hyg. Assoc. J., vol. 35, pp. 165 174, March 1974
[13] H. W. Alter and R. L. Fleischer, "Passive integrating radon monitor for environmental monitoring," Health Phys., vol. 40, pp. 693-702, May 1981.

[14] A. C. George, "Passive integrated measurement of indoor radon using activated carbon," Health Phys., vol. 46, pp. 867-872, April 1984.

[15] B. L. Cohen and R. Nason, "A diffusion barrier charcoal adsorption collector for measuring $\mathrm{Rn}$ concentrations in indoor air," Health Phys., vol. 50, pp. 457-463, April 1986.

[16] H. M. Prichard and K. Marien, "A passive diffusion $222 \mathrm{Rn}$ sampler based on activated carbon adsorption," Health Phys., vol. 48, pp. 797-803, June 1985.

[17] P. Kotrappa, J. C. Dempsey, J. R. Hickey, and L. R. Stieff, "An electret passive environmental $222 \mathrm{Rn}$ monitor based on ionization measurement," Health Phys., vol. 54, pp. 47-56, Jan. 1988.

[18] F. J. Guggenheim, A. C. George, R. T. Graveson, and A. J. Breslin, "A time-integrating environmental radon daughter monitor," Health Phys., vol. 36, pp. 452-455, March 1979.

[19] J. W. Thomas and R. J. Countess, "Continuous radon monitor," Health Phys., vol. 36, pp. 734-738, June 1979.

[20] A. Busigin, A. Van Vooren, and C. R. Phillips, "Interpretation of the response of continuous radon monitors to transient radon concentrations," Health Phys., vol.37, pp. 659-667, Nov. 1979.

[21] P. Chittaporn, M. Eisenbud, and N. H. Harley, "A continuous monitor for the measurement of environmental radon," Health Phys., vol. 41, pp. 405-410, August 1981.

[22] N. Latner, S. Watnick, and R. T. Graveson, "Integrating working level monitor EML Type TF11," USDOE Report EML-389, New York, NY, Jan. 1981. 